\title{
KEGIATAN MEDIA RELATIONS MAYAPADA HEALTHCARE GROUP DALAM MEMBENTUK CITRA MAYAPADA HOSPITAL
}

\author{
Rahma Nurrani Annisa, Gracia Rachmi Adiarsi \\ London School of Public Relations (LSPR), Jakarta \\ rahmanurraniannisa95@yahoo.com,gracia.ra@lspr.edu
}

\begin{abstract}
Hospitals are health institutions such as other institutions that engage with media (media relations). Mayapada Healthcare Group is one of the groups that handle several hospitals Mayapada make connections with the media in order to help the formation of the desired image (wish images) the institution. Public Relations Division of the Mayapada Health Care group has just conducted media relations for a period of 1 year. The purpose of this study is to describe the process and implementation of Mayapada Healthcare Group media relations activities in an effort to form the image of Mayapada Hospital. The theory used in this research is media relations and image. The research method uses a qualitative approach with data collection through in-depth interviews from informants. The results of this study illustrate that the results of media relations form the image as Mayapada Hospital expectations, namely as a hospital that has a unity of good and complementary, seen from the factors of physical identity, non-physical identity, quality results, quality and service, and activities and patterns of relationships based on news about Mayapada Hospital
\end{abstract}

Keywords: Media relations, image, hospital

\begin{abstract}
ABSTRAK
Rumah sakit merupakan institusi kesehatan seperti institusi lainnya yang melakukan hubungan dengan media (media relations). Mayapada Healthcare Group merupakan salah satu kelompok yang menangani beberapa rumahsakit Mayapada melakukan hubungan dengan media guna membantu pembentukan citra yang diharapkan (wish images) pihak institusi tersebut. Divisi Public Relations grup Mayapada Health Care baru melaksanakan hubungan dengan media (media relations) selama kurun waktu 1 tahun. Tujuan penelitian ini adalah untuk mendeskripsikan proses dan pelaksanaan kegiatan hubungan dengan media (media relations) Mayapada Healthcare Group dalam usahanya membentuk citra Mayapada Hospital. Konsep yang digunakan dalam penelitian ini ialah hubungan media dan citra. Adapun metode penelitian menggunakan pendekatan kualtitatif dengan pengumpulan data melalui wawancara mendalam (indepth interview) kepada nara sumber. Hasil penelitian menggambarkan bahwa hasil dari hubungan dengan media (media relations) membentuk citra sesuai harapan Mayapada Hospital, yaitu sebagai rumah sakit yang memiliki satu kesatuan yang baik dan saling melengkapi, dilihat dari faktor identitas fisik, identitas non fisik, kualitas hasil, mutu dan pelayanan, dan aktivitas dan pola hubungan berdasarkan pemberitaan mengenai Mayapada Hospital.
\end{abstract}

Kata kunci: Media relations, citra, rumah sakit 


\section{PENDAHULUAN}

Saat ini divisi Public Relations dibutuhkan oleh seluruh perusahaan dalam berbagai bidang. Public Relations memiliki rekan yang tidak dapat dipisahkan yang terdapat hubungan yang menguntungkan antara satu sama lain yaitu media massa.

Komunikasi yang dimiliki oleh Public Relations harus dilakukan secara tertata dengan baik dan terstruktur sehingga media akan merasa lebih nyaman berpartisipasi dalam kegiatan media relations. Hubungan yang sudah terjalin baik dengan media dapat membantu untuk membangun, menjaga, dan meningkatkan citra atau reputasi organisasi di mata stakeholder (Isni, 2012, p. 88).

Citra yang baik dari suatu perusahaan atau organisasi merupakan aset, karena berdampak terhadap efektifitas komunikasi dan operasional organisasi atau perusahaan dalam berbagai segi (Yuningsih, 2005, p.316). Perusahaan akan lebih diberimendapat kepercayaan dari pihak eksternal perusahaan tersebut dan pembicaran positif mengenai perusahaan akan tersebar luas.

Salah satu perusahaan yang bergerak dibidang kesehatan yang ingin membentuk citra dari sisi pihak ekternal, melalui kegiatan media relations adalah Rumah Sakit Mayapada (Mayapada Hospital). Mayapada Hospital memilki keunggulan yaitu telah membangun dan mengoperasikan sebelas Center of Excellence. Tidak hanya itu, Mayapada Hospital memiliki peralatan-peralatan yang up to date seperti Operating Theater, Cathlab, fasilitas penunjang lain seperti laboratorium yang modern, perlengkapan MRI, CT Scan, dan ahli medis yang kompeten di bidang tertentu (Tribunnews, 2013, Oktober 25). Mayapada Healthcare Group yang menaungi dua rumah sakit, telah terakreditsi lulus PARIPURNA oleh KARS versi 2012, mendapatkan penghargaan BKBN pada tahun 2015 (Kurnia, 2016, April 26).

Mayapada Healthcare Group dikenal karena adanya Tahir Foundation yang sudah mengucurkan total dana senilai US \$ 100 Juta, dalam kurun lima tahun untuk penanganan medis yang bekerja sama dengan orang terkaya di dunia yaitu Bill Gates (Azizah, 2015, Maret 30).

Mayapada mendirikan Mayapada Healthcare Group (MHG) pada bulan Maret 2015, dimana dalam group tersebut terdapat beberapa divisi, termasuk Head of Corporate Communications. Divisi Head of Corporate Communications disebut juga sebagai Public Relations pada MHG, memiliki tugas khusus untuk membentuk citra Mayapada Hospital dan keharusan untuk menjalin hubungan baik dengan media melalui kegiatankegiatannya (media relations). 
Berdasarkan pra-riset yang dilakukan oleh peneliti Mayapada Hospital sudah terdapat public relations di setiap unitnya, tetapi tidak memaksimalkan fungsi public relations. Setelah adanya divisi public relations pada tahun 2016 di MHG, menurut Dewi Yuany selaku Public Relations di MHG, barulah memfokuskan untuk menjalin hubungan dengan pihak luar, terutama dengan media dan berusaha untuk membentuk citra yang diinginkan Mayapada Healthcare Group.

Kegiatan media relations yang baru dilakukan selama satu tahun lebih sudah mempunyai beberapa koneksi dengan media-media besar di Indonesia, seperti: Bisnis Indonesia, Jawapos, Kontan, The JakartaPos, detik.health, Swa Magazine, Media Indonesia, dan beberapa media cetak ataupun online lainnya. Dengan kegiatan tersebut terciptanya berita yang lebih mengarah ke arah positif, dan membantu untuk usahanya membentuk citra Mayapada Hospital yang semakin lebih baik.

Menurut Jonathan Tahir selaku CEO Mayapada Healthcare Group (Lilyah, 2016, Mei 5), pada saat melakukan salah satu kegiatan media relations, yaitu one on one interview, mengatakan bahwa masyarakat memandang Mayapada Hospital sebagai rumah sakit untuk kalangan premium atau atas saja. Tahir menekankan bahwa Mayapada Hospital memberikan tarif yang wajar, dan kedepannya dari pihak Mayapada ingin mendalami konsep layanan yang lebih terjangkau untuk semua kalangan. Dari kegiatan media relations tersebut diharapkan dapat membentuk citra yang sesuai dengan yang diinginkan oleh pihak Mayapada.

Berdasarkan uraian tersebut gambaran mengenai bagaimana proses dan pelaksanaan kegiatan media relations Mayapada Healthcare Group dalam usahanya membentuk Citra Mayapada Hospital menjadi suatu hal yang menarik untuk diteliti. Penelitian ini mendeskripsikan proses sebelum pelaksanaan, pelaksanaan dan sesudah kegiatan media relations dilakukan.

\section{TINJAUAN PUSTAKA}

Salah satu penelitian yang berkaitan dengan topik ini adalah dari jurnal Komunikasi ASPIKOM, volume 2, nomor 5, Tahun 2015, karya Nugrahaning Esa Pratiwi, Richard Gordon Mayopu, dan George Nicholas Huwae, yang berjudul "Aktivitas Media Relations Humas Setda Kota Salatiga Dalam Membentuk Berita Positif". Teori yang digunakan adalah public relations dan media relations. Hasil penelitian ini adalah aktivitas media relations informal lebih berperan dalam membentuk berita positif tentang pemerintahan Kota Salatiga di media cetak karena dapat menciptakan hubungan baik antara humas dan jurnalis. Penelitian lainnya yaitu dari Jurnal Ilmu Komunikasi Volume 13, Nomor 13, Universitas Mercu buana dan Universitas Tarumanegara Tahun 2015, karya Nur Kholisoh dan Yenita, yang berjudul Strategi Public Relations dan citra positif organisasi (Kasus 
Public Relations Rumah Sakit "X" di Jakarta. Teori yang digunakan adalah komunikasi pemasaran, public relations dan citra.

Frank Jeffkins (Morrisan, 2010, p.8) mengatakan bahwa Public Relations adalah sesuatu yang merangkum keseluruhan komunikasi yang terencana, baik itu ke dalam ataupun ke luar antara suatu organisasi dengan semua khlayaknya dalam rangka mencapai tujuantujuan spesifik yang berlandaskan pada saling pengertian.

Public Relations (PR) menurut Maria (Suryanto, 2015, p.433) mempunyai fungsi untuk memperoleh timbal balik positif ada nya rasa saling percaya satu sama lain dan juga citra positif dari publik atau masyarakat luas. Selain itu juga untuk membuat opini publik yang tepat, sehingga dapat diterima dan mengutungkan semua pihak melalui sasaran yang tepat. Fungsi PR juga membuat serta menjalin hubungan yang kuat dan harmonis antara perusahaan dengan publik. Tujuan perusahaan yang dicapai diharapkan sesuai dengan harapan publik, tetapi tidak menghilangkan ciri khas perusahaan.

\section{Media Relations}

Untuk memperoleh citra positif sebuah perusahaan melakukan komunikasi dengan publik melalui media massa. Agar aktivitas Public Relations dapat dipublikasikan oleh media maka PR perlu menjalin hubungan yang baik dengan pihak media. Ruslan (dalam Yuliana, 2014, p.91) memberi definisi media relations sebagai kegiatan yang dilakukan khusus oleh public relations dalam melakukan komunikasi penyampaian pesan atau informasi seputar aktivitas yang bersifat kelembagaan, perusahaan/institusi , produk sampai kegiatan yang bersifat individual yang perlu dipublikasikan, dengan cara mengajak kerjasama pihak pers atau media massa untuk mendapatkan publisitas dan citra positif.

Soemirat and Ardianto (2015, p.128) menjelaskan terdapat beberapa jenis kegiatan media relations sebagai berikut :

- Konferensi Pers (Press Conference) adalah suatu kegiatan yang para jurnalis dengan berkumpul bersama, membicarakan topik yang sedang hangat dibicarakan dan mempunyai nilai berita yang penting disuatu perusahaan/instansi/badan atau permintaan dari para wakil pers.

- Press briefing merupakan sebuah kegiatan yang dilakukan oleh public relations di sebuah perusahaan. Di dalam kegiatan ini public relations menyampaikan beberapa informasi mengenai kegiatan yang baru terjadi kepada pers, dan wartawan diberi kesempatan untuk bertanya apabila ada keterangan yang belum dijelaskan secara terperinci.

- Press Tour adalah kegiatan yang diselenggarakan oleh pihak perusahaan dengan mengundang media untuk mengunjungi wilayah tertentu yang berkaitan dengan perusahaan, sambil berwisata melihat-lihat pabrik yang dimiliki pribadi oleh institusi/perusahaan. 
- Press Release adalah alat publisitas yang digunakan oleh organisasi kepada media, Untuk menyebarkan sebuah berita mengenai organisasi. Kegiatan ini lebih efektif, karena dapat menghemat biaya dibandingkan dengan konferensi pers dan kunjungan media.

- Special Event yaitu sebuah kegiatan khusus penting yang dilakukan oleh public relations dengan memberikan kepuasan bagi banyak orang untuk ikut berpartisipasi dalam suatu kesempatan yang mampu menambah pengetahuan dan memenuhi kebutuhan publik, dan tidak lupa dalam kegiatan ini public relations mengundang pers.

- Press Luncheon adalah pejabat public relations mengundang beberapa wartawan untuk mengikuti jamuan makan siang dengan top management perusahan, sehingga wartawan dapat mengetahui perkembangan perusahaan/lembaga tertentu.

- Wawancara Pers adalah suatu kegiatan yang berasal dari inisiatif media sendiri dengan menyiapkan pertanyaan khusus untuk mewawancarai seorang pejabat public relations atau dengan top management perusahaan yang bersifat lebih pribadi.

Adapun kegiatan yang dilakukan suatu organisasi dalam membina hubungan baik dengan media tentu ada tujuan tertentu seperti berikut ini.

\section{Tujuan Media Relations}

Kegiatan media relations yang dilakukan oleh public relations terhadap media, memiliki beberapa tujuan (Yuliana 2014, p.93) yaitu:

- Meningkatkan kesadaran, seperti halnya kesadaran merek (brand awareness).

- Mengubah sikap dari seseorang yang tidak suka atau anti menjadi netral, dan dari netral diubah menjadi sikap yang mendukung terhadap kegiatan yang dilakukan organisasi.

- Mendorong sebuah tindakan, misalnya sikap yang mendukung segala kebijakan dari proses produksi yang ramah lingkungan yang dilakukan oleh organisasi.

\section{Citra}

Menurut Soemirat dan Adrianto (Gassing \& Suryanto, 2016, p.156), definisi citra adalah kesan seseorang atau individu tentang sesuatu yang muncul sebagai hasil dari pengetahuan dan pengalamannya. Adapun faktor pembentukan citra perusahaan, menurut Gassing \& Suryanto (2016) yaitu identitas fisik, identitas non fisik, kualitas hasil, mutu dan pelayanan serta aktivitas dan pola hubungan.

Identitas fisik yang dimaksud ialah organisasi atau institusi perusahaan dapat dilihat secara fisik melalui pengenalan visual, audio, dan media komunikasi yang digunakan. Pengenalan visual seperti nama yang melekat, logo, gedung, desain ruangan, warna dan loby sebuah kantor. Sedangkan yang dimaksud dengan identitas nonfisik ialah identitas 
organisasi yang berhubungan dengan apa yang tidak bisa dilihat oleh kasat mata misalnya, sejarah, filosofi, budaya di dalam organisasi, susunan manajemen, kepercayaan dan nilai kemanusiaan yang ditanamkan.

Mutu produk juga merupakan faktor pembentuk citra dalam organisasi. Dapat diartikan bahwa sebuah produk yang dirancang baik barang atau jasa, mencerminkan kualitas manajemen. Semakin organisasi dapat mempertahankan dan mutu produk, semakin baik citra sebuah perusahaan di mata konsumen.

Aktivitas dan pola hubungan ialah semua aktivitas dan pola hubungan dengan individu, jaringan dan sumber daya diluar organisasi mencerminkan citra organisasi. Pola dasar yang harus dilakukan adalah memberikan respon jujur dan memperhatikan tanggung jawab (Gassing \& Suryanto, 2016).

Sebuah perusahaan apabila memiliki citra yang kuat dan baik di mata publik akan mempunyai manfaat dan keuntungan untuk organisasi itu sendiri. Manfaat citra perusahaan menurut Siswanto Sutojo (Gassing\&Suryanto, 2016, p.156), sebagai berikut

- Daya saing jangka menengah dan panjang yang mantap

Sebuah organisasi atau institusi perusahaan apabila sudah memilki citra yang baik, tidak akan mudah di tiru identitas atau kepribadian perusahaan tersebut, sehingga dapat terlindung dari pesaing.

- Menjadi perisai selama masa krisis.

Pada saat terjadi krisis perusahaan yang telah memiliki citra positif dan melakukan sebuah kesalahan, akan lebih mudah di maafkan oleh masyarakat dan diberikan kesempatan kedua.

- Menjadi daya tarik eksekutif andal

Sebuah perusahaan dengan citra yang baik dapat menarik para eksekutif andal yang merupakan aset untuk alat penggerak perusahaan.

- Meningkatkan efektivitas strategi pemasaran

Kegiatan strategi pemasaran tidak perlu dillakukan dalam kondisi besar-besaran tidak seperti pada saat perusahaan belum memiliki citra.

- Penghematan biaya operasional

\section{METODOLOGI PENELITIAN}

Penelitian ini menggunakan metode penelitian deskriptif dengan pendekatan kualitatif. Denzin dan Lincoln menjelaskan yang dimaksud dengan penelitian kualitatif adalah penelitian yang menggunakan latar alamiah, dengan maksud menafsirkan fenomena yang terjadi dan dilakukan dengan jalan melibatkan berbagai metode yang ada (Moleong, 
2010). Moleong (2010) menambahkan bahwa metode penelitian deskriptif dengan pendekatan kualitatif, data yang dikumpulkan berupa kata-kata, gambar dan bukan angka-angka.

Pengumpulan data primer dengan melakukan wawancara kepada narasumber internal yaitu Dewi Yuany selaku Head of Corporate Communication MHG dan narasumber eksternal diantaranya yaitu: Nurvita Indarini selaku Managing Editor detikhealth, Lisvy Nael selaku Wartawan Jawa Pos, Elisabet Lisa Listiani Putri selaku Reporter Kontan, dan Joshua Astono selaku Pembaca Berita.

Pengumpulan data sekunder dilakukan dengan referensi yang tersedia dari perpustakaan, jurnal, internet, data internal perusahaan dan sumber lain yang mendukung penelitian ini.

Data yang telah terkumpul dianalisis dengan menggunakan model Miles \& Huberman (2014, p.8-9), dengan melalui tahap reduksi data, penyajian data, dan penarikan kesimpulan.

\section{HASIL DAN PEMBAHASAN}

\section{Fungsi Public Relations Mayapada Healthcare Group}

Menurut Maria (Suryanto, 2015, p.433), salah satu fungsi public relations adalah memperoleh timbal balik positif, adanya rasa saling percaya satu sama lain dan juga citra positif dari publik atau masyarakat luas, serta menjalin hubungan yang kuat dan harmonis antara perusahaan dengan publik.

Berdasarkan informasi yang diperoleh dari Dewi Yuany selaku Head of Corporate Communication dari Mayapada Healthcare Group, mengatakan bahwa fungsi public relations Mayapada Healthcare Group yaitu, membentuk sebuah citra dari Mayapada Healthcare Group, dengan cara memfokuskan kepada hubungan dengan media saja, yaitu berupa kegiatan media relations yang dilakukan dari pihak Mayapada, sehingga dari kegiatan tersebut diharapkan dapat menginformasikan segala sesuatunya kepada khalayak luas melalui media..

\section{Media Relations}

Dewi Yuany selaku Head of Corporate Communication menjelaskan bahwa dia baru bergabung di Mayapada Healthcare Group (MHG) sejak tahun 2016, dan melakukan kegiatan media relations sejak tahun 2016. Sebelum ia bergabung dengan MHG, Mayapada Healthcare Group belum mempunyai seorang public relations yang terpusat dalam arti hanya ada public relations di masing-masing rumah sakit dibawah naungan Mayapada saja. Tidak dilakukannya kegiatan media relations secara intens dan kurang 
maksimalnya fungsi PR. Sejak Dewi bergabung dalam grup Mayapada Healthcare barulah MHG secara aktif membuka portal untuk menghubungkan dengan media.

Nara sumber dari pihak JawaPos dan Kontan mengatakan bahwa mengenal Mayapada Hospital dan berpartisipasi dalam kegiatan serta menjalin hubungan dengan public relations Mayapada Healthcare Group sejak awal tahun 2016.

Berbeda dengan dengan JawaPos dan Kontan, detik.health sudah mengenal Mayapada Hospital dan menjalin hubungan dengan public relations Mayapada Hospital sejak tahun 2013 sebelum adanya public relations di MHG. Menurut detik.health pihaknya hanya mewawancarai dokter sewaktu ada berita terkait seorang artis yang berhasil di operasi di Mayapada Hospital.

Kegiatan media relations yang dilakukan antara lain dengan kunjungan ke media (media visit) ke kantor detik.com yang dilakukan sejak awal bulan April tahun 2016. Mayapada dan detik.com memiliki kecocokan terhadap misi yang sama yaitu mengedukasi masyarakat tentang kesehatan. Oleh sebab itu disepakati kegiatan media relations lainnya seperti live chat dan kegiatan lainnya.

\section{Pentingnya Media Relations}

Dewi Yuany selaku Head of Corporate Communication dari Mayapada Healthcare Group mengatakan bahwa kegiatan media relations merupakan salah salah satu alat penting yang sudah menjadi kewajiban yang dilakukan oleh pihak Mayapada, agar dapat membantu menjembatani hubungan antara Mayapada Hospital dengan publik dan media, serta untuk membangun dan mempertahankan sebuah citra positif.

\section{Proses Sebelum Kegiatan Media Relations}

Menurut Dewi Yuany dari MHG dan Lisvy Nael wartawan di JawaPos, public relations mengatakan bahwa Mapada Healthcare Group pada saat mengundang media lebih ke informal yaitu melalui whatsapp, karena antara public relations Mayapada Healthcare Group dan beberapa media sudah memiliki hubungan personal sebelumnya. Jika mengundang dengan proses formal menggunakan $e$-mail. Cara lain yang digunakan untuk mempertemukan perwakilan Mayapada Healthcare Group dengan pimpinan redaksi media dengan tatap muka untuk merundingkan kesepakatan kegiatan media relations yang akan dilakukan kedua pihak.

\section{Pelaksanaan Kegiatan Media Relations}

Berbeda dengan Soemirat dan Ardianto (2015) yang menyatakan bahwa kegiatan media relations terdiri dari press conference, press briefing, press tour, press release, special event, press luncheon, dan press interview, Public Relations MHG menyelenggarakan kegiatan media relations, sebagai berikut:

- Press Conference: Kegiatan press conference telah dilakukan sebanyak 4 kali, dalam jangka waktu 15-30 menit. Kegiatan ini dilakukan untuk mengkomunikasikan 
suatu informasi penting atau kegiatan besar yang telah dilakukan kepada pihak eksternal Mayapada, seperti isu kesehatan serta perkembangan bisnis dari Mayapada Healthcare Group. Banyak media yang datang untuk meliputi kegiatan tersebut, terutama media online, dan setelah 1 jam kegiatan press conference berlangsung berita nya langsung naik.

- Hospital Tour: Kegiatan hospital tour sampai saat ini telah dilakukan 2 kali. Media yang mengikuti press tour sangat terbatas, yaitu 4-6 media saja. Kegiatan yang biasa dilakukan yaitu memperkenalkan fasilitas-fasilitas serta keunggulan yang dimiliki oleh Mayapada Hospital, selain itu memberikan kesempatan bagi media yang hadir untuk memeriksakan kesehatan nya secara langsung di rumah sakit. Kegiatan press tour yang dilakukan pihak Mayapada lebih ke arah informal dan santai, karena acara diakhiri dengan makan siang dan sesi ngobrol atau sharing dengan pihak direksi atau CEO, seperti pak Jonathan Tahir dan dokter-dokter senior yang biasanya mengepalai setiap department.

- Press Release: Pihak PR dari Mayapada Healthcare Group memberikan sebuah press release terhadap media pada saat kegiatan media relations berlangsung dalam bentuk hard copy, dan setelah kegiatan media relations dalam bentuk soft copy. isi atau informasi yang terdapat dalam press release tersebut adalah quotation atau kutipan dari spokes person Mayapada, informasi mengenai kegiatan media relations apa yang pada saat itu dilakukan, tips-tips pengetahuan dan seputar kesehatan, dan selalu diselipkan informasi mengenai rumah sakit. Tetapi berbeda dengan media bisnis seperti Kontan bahwa informasi yang terdapat di dalamnya yaitu bagaimana kerjasama antara pihak Mayapada dengan sebuah organisasi atau rumah sakit, kerja sama dalam bentuk apa, atau isi kesepakatan nya seperti apa, serta contact person dari pihak Mayapada, sehingga apabila media kurang jelas dengan informasi yang terdapat di dalam press release, dapat langsung menanyakan kejelasan kepada kontak yang tertera dalam press release.

- Media Gathering: Kegiatan media gathering telah dilakukan sebanyak 1 kali. Peserta media gathering dihadiri sebanyak 15-20 media. Kegiatan yang dilakukan lebih ke acara ramah tamah. Kegiatan dilakukan pada saat hari raya besar tertentu, seperti idul fitri maupun buka puasa bersama, dan media-media yang diundang merupakan media yang terpilih, seperti media bisnis, kesehatan dan lifestyle yang dibutuhkan. Dilihat dari pandangan media JawaPos dan detik.health proses kegiatan media gathering yang dilakukan oleh pihak Mayapada yaitu pertama kali memperkenalkan jajaran direksi, lalu memiliki informasi mengenai isu-isu kesehatan dan dilanjutkan dengan makan bersama, dan juga terdapat pemeriksaan kesehatan bagi para media yang datang, lalu informasi yang diperoleh dapat langsung ditulis oleh media berupa tulisan artikel.

- One on One Interview: Kegiatan one on one interview sudah dilakukan sebanyak 14 kali. Kegiatan ini merupakan kegiatan yang mewawancarai secara ekslusif seorang CEO dari Mayapada Healthcare Group mengenai seputar keseharian beliau dan gaya kepemimpinan beliau, atau bisa juga perkembangan bisnis Mayapada Healthcare Group atau mengenai industri kesehatan. Untuk media dengan 
segmentasi kesehatan seperti JawaPos dan detik.health tidak pernah mengikuti kegiatan one on one interview dengan pak Jonathan Tahir. Sedangkan untuk media yang mempunyai segmentasi bisnis seperti koran Kontan sudah pernah melakukan kegiatan one on one interview dengan pak Jonathan Tahir selaku CEO Mayapada Helathcare Group yang membahas mengenai perkembangan Mayapada Hospital.

- Live Chat: Kegiatan live chat telah dilakukan sebanyak 4 kali. Kegiatan ini berisikan informasi penting yang disampaikan sesuai tema yang dibutuhkan melalui perantara detikhealth. Live chat merupakan kegiatan media relations yang dianggap paling efektif untuk membentuk citra Mayapada Hospital, karena pada saat dokter-dokter menjawab pertanyaan secara langsung sesuai dengan ekspektasi dan kebutuhan informasi detikers, dapat membentuk kepercayaan kepada dokter-dokter Mayapada Hospital yang memiliki kredibilitas tinggi. Pada saat kegiatan live chat dilakukan banyak yang bertanya dan puas akan jawaban yang diberikan oleh dokter Mayapada Hospital. Pertanyaan yang diajukan sampai membludak dan pada saat waktu habis untuk melakukan kegiatan live chat. Kegiatan live chat memiliki keuntungan bagi masyarakat, media dan juga Mayapada Hospital, yaitu mereka mendapatkan ilmu dan pengetahuan yang lebih mengenai kesehatan yang belum pernah mereka ketahui sebelumnya, sedangkan bagi Mayapada Hospital yaitu rumah sakit ini lebih dikenal dengan dokter-dokter yang memiliki kredible tinggi, yang secara langsung dapat mempengaruhi citra Mayapada Hospital.

- Sponsorship: Kegiatan sponsorship telah dilakukan sebanyak 12 kali. Kegiatan sponsorship yang dimaksud oleh PR dari Mayapada bukan dalam bentuk uang, tetapi jasa, dengan menyediakan dokter-dokter terbaik untuk menjadikannya sebagai narasumber yang memberikan sebuah informasi seputar kesehatan, tergantung topik apa yang ingin dibicarakan oleh media yang dituju. Menurut pihak dari detik.health dan JawaPos kegiatan sponsorship berupa MCU gratis dalam bentuk voucher, dan selalu memberikan dokter-dokter yang informative dan sesuai kebutuhan media.

- Media Visit: Media visit telah dilakukan sebanyak 10 kali. Kegiatan ini bertujuan untuk memperkenalkan diri lebih dalam mengenai Mayapada Hospital, serta ingin bertukar pikiran satu sama lain mengenai bisnis dan industri kesehatan. Mediamedia yang pernah ikut berpartisipasi yaitu: The Jakarta Post, Media Indonesia, Bisnis Indonesia, Swa, Koran Tempo, Detik.com, JawaPos. Menurut kedua media JawaPos dan detik.health kegiatan media visit dihadiri oleh beberapa perwakilan Mayapada Healthcare Group seperti CEO, Direktur atau General Manager dan PR Mayapada Healthcare Group. Keuntungan dari kegiatan media visit menurut PR Mayapada Healthcare Group yaitu biasanya media langsung memberitakan atau membuat artikel seputar informasi yang didapat dari kegiatan media visit.

Berdasarkan penjelasan pihak PR Mayapada Healthcare Group, tidak dilakukannya press briefing, special event dan press interview ialah karena pihak PR menganggap bahwa press 
briefing sama dengan kegiatan yang sudah dilakukan yaitu hospital tour, sedangkan untuk special event pihak PR mengangap kegiatan tsb seperti live chat. Adapun wawancara pers (press interview) tidak diadakan karena dianggap sama dengan kegiatan one on one interview. Semua kegiatan yang belum dilakukan seperti yang telah disebutkan sudah terganti dengan acara yang hampir serupa.

\section{Proses Setelah Kegiatan Media Relations Berlangsung}

Dewi Yuany selaku Head of Corporate Communication MHG menjelaskan bahwa setelah kegiatan media relations selesai dilakukan, press release baru diberikan kepada media dalam bentuk hard copy dan juga soft copy. Lisvy Nael wartawan JawaPos mengatakan bahwa selain mendapatkan press release MHG memberikan press kit yang berisi profiling Mayapada dan souvenir yang mencerminkan Mayapada. Souvenir berupai mug, tempelan, pulpen, notes, majalah internal Mayapada Healthcare Group.

Head of Corporate Communication Mayapada Healthcare Group mengatakan setelah kegiatan media relations diselenggarakan maka pihak PR melakukan evaluasi dari coverage berita yang telah dimuat oleh media. Hal ini dapat dijadikan bahan pembelajaran untuk kedepannya. Juga dilakukan review melihat pemberian press release dan saat pelaksanaan press conference, apakah terdapat penyampaian yang kurang memiliki news value atau sudah cukup sesuai dengan kebutuhan media.

Dari sisi media, setelah kegiatan media relations telah usai, hal yang mereka lakukan adalah meringkas informasi penting apa saja yang didapat dan mempublikasikan informasi yang diperoleh dari kegiatan tersebut.

\section{Pemberitaan di Media dalam Membentuk Citra}

Menurut Nurvita Indarini selaku Managing Editor detik.health, Lisvy Nael wartawan JawaPos dan Elisabet Lisa selaku reporter koran Kontan, pemberitaan dapat membuat citra rumah sakit menjadi lebih baik dimata pihak eksternal. Informasi yang terdapat di media membahas secara fakta mengenai rumah sakit antara lain dokter-dokter dalam memberikan informasi kesehatan yang membuat orang berfikir bahwa rumah sakit tersebut memiliki dokter yang capable dan credible. Media bisnis yang membahas mengenai informasi seputar bisnis dijalankan oleh sebuah rumah sakit akan membentuk opini publik atau pihak eksternal bahwa rumah sakit tersebut memiliki sebuah bisnis bersih dan terpercaya.

\section{Citra yang Ingin Dibentuk oleh Mayapada Hospital}

Dewi Yuany menjelaskan citra yang ingin dibentuk dilihat dari semua aspek baik dari segi dokter, perawat, management rumah sakit, layanan (service), infrastruktur, serta aspek bergerak dan tidak bergerak lainnya, karena semua aspek tersebut merupakan satu kesatuan yang tidak dapat dipisahkan, dan ingin menonjolkan segala aspek tersebut secara baik. Penampilkan citra sebagai rumah sakit yang mengedukasi publik eksternal mengenai industri kesehatan. 


\section{Citra yang Terbentuk oleh Media dan Pembaca Berita}

Menurut Gassing \& Suryanto (2016) citra terbentuk dari beberapa faktor yang mendukung. Dari kegiatan media relations yang telah dilakukan, terbentuklah citra Mayapada Hospital, dari sisi pandangan media yang ikut berpartisipasi langsung dalam kegiatan media relations, maupun pembaca yang memiliki pandangan khusus berupa citra dari apa yang dibaca di berita online dan cetak, yaitu:

- Identitas Fisik: Menurut sisi pandang media (detikhealth, JawaPos, Kontan) dan pembaca, logo yang terlihat dari Mayapada Hospital yaitu sederhana, mudah di ingat dan cukup mewakili, serta dilihat dari logonya yang berlambang hati mengartikan bahwa rumah sakit ini mengutamakan pelayanan yang baik dengan penuh kasih kepada pasien-pasiennya. Dilihat dari segi fasilitas nya Mayapada Hospital adalah sebuah rumah sakit yang memiliki satu kesatuan, yang saling mendukung dan melengkapi satu sama lain dengan baik, karena memiliki gedung yang dan peralatan yang modern, fasilitas yang bersih, nyaman, tidak kumuh, banyak halaman luas, tempat parkir baik, dan lingkungan nya lumayan hijau, dan memberikan kenyaman bagi pasiennya seperti layaknya dirumah, dan untuk lokasi Mayapada Hospital Tangerang cukup unik, karena berada di kawasan perumahan Modern Land Tangerang.

- Identitas Non Fisik (Sejarah Mayapada Hosiptal, budaya yang diterapkan rumah sakit, sistem punish and reward, susunan manajemen, kepercayaan dan nilai kemanusiaan): Pendapat yang sama dari ketiga media yang menjadi narasumber mengenai citra Mayapada Hospital dilihat dari segi identitas non fisik yaitu ketiga media ini belum begitu mengetahui secara jelas mengenai sejarah Mayapada Hospital, tetapi mereka lebih melihat kepada sejarah dari owner Mayapada Group yang telah memiliki banyak pengalaman di dunia bisnis yang selama ini berjalan dengan baik, yang berkaitan dengan kegiatan filantropi, sehingga berpengaruh juga terhadap citra yang dilihat dari Mayapada Hospital sebagai rumah sakit yang memiliki kesejahteraan dan rumah sakit yang lebih mementingkan pelayanan ketimbang hanya sekedar mencari uang. Citra non fisik lainnya seperti budaya rumah sakit ini dianggap memiliki budaya keramah-tamahan dengan pihak eksternal nya. Dilihat dari segi penghargaan-penghargaan yang diperoleh Mayapada Hospital membuat citra Mayapada Hospital terlihat bersungguhsungguh dalam menjadi suatu tempat tujuan pelayanan kesehatan.

- Kualitas Hasil, Mutu dan Pelayanan yang Memuaskan: Citra yang dilihat dari segi kualitas hasil, mutu citra yang dilihat melalui narasumber atau dokter-dokter terbaik yang menjadi pembicara dalam kegiatan media relations tertentu, selalu menyajikan informasi yang memiliki news value bagi media, dan bagi pendengar dan pembaca merasa mendapatkan pengetahuan lebih mendalam mengenai sebuah informasi kesehatan yang sebelumnya mereka tidak ketahui, atau bahkan belum diketahui kebeneran informasi tersebut. Sedangkan untuk pelayanannya citra yang dilihat selalu memberikan fasilitas yang baik dan koperatif terhadap media. menghormati customer, dan dalam menyediakan informasi selalu menyediakan dengan cepat dan terbuka. 
- Aktivitas dan Hubungan yang Baik Kepada Pihak Eksternal Rumah Sakit: Citra yang dilihat dari segi aktivitas yaitu sebagai rumah sakit bertaraf internasional karena Mayapada Hospital selalu memiliki aktivitas kerja sama dengan beberapa rumah sakit internasional. Dari segi hubungan citra yang terlihat, Mayapada Hospital sampai saat ini masih memiliki hubungan baik dengan pihak ekternal media maupun masyarakat, sehingga belum ada isu-isu negatif mengenai kegiatan yang Mayapada lakukan.

Menurut Dewi Yuany selaku Head of Corporate Communication adanya rencana tambahan kegiatan media relations yaitu seminar untuk media, dimana kegiatan tersebut bertujuan untuk mengedukasi media tentang kesehatan, sehingga media mendapatkan pengetahuan lebih mengenai isu-isu berkaitan dengan kesehatan.

\section{Hal yang Membuat Media Tertarik untuk Meliput Berita Mengenai Mayapada Hospital}

Menurut Nurvita Indarini selaku Managing Editor detik.health, Lisvy Nael selaku wartawan JawaPos, dan Elisabet Lisa selaku reporter koran Kontan, hal yang menarik bagi media untuk meliput Mayapada Hospital yaitu, karena Mayapada memiliki dokterdokter yang memberikan penjelasan secara rinci dengan menggunakan bahasa umum yang mudah dimengerti. Dokter Mayapada Hospital tidak sombong dan tidak menggurui, seperti rumah sakit lain dimana terdapat dokter yang kurang menjelaskan secara rinci dan terkesan menggurui, mudah untuk meminta narasumber apabila sedang dibutuhkan. Mayapada Hospital termasuk di dalam sebuah group bisnis besar, dengan kapitalisasi pasar dengan cukup besar dan berkembang dengan cukup besar, mempunyai visi misi yang baik dan merupakan perusahaan yang terbuka.

\section{Pemberitaan yang Terdapat di Media mengenai Mayapada Hospital}

Menurut Nurvita Indarini selaku Managing Editor detik.health dan juga Lisvy Nael selaku wartawan JawaPos menjelaskan bahwa, kedua media ini hanya memberitakan mengenai isu-isu kesehatan yang disampaikan oleh dokter-dokter Mayapada Hospital, karena mereka merupakan media yang bersegmentasi pada kesehatan. Sedangkan media bisnis dilihat dari perkembangan bisnis Mayapada Hospital. Dilihat dari segi pembaca membenarkan bahwa berita yang sering berada di media adalah mengenai isu kesehatan dan ekspansi yang dilakukan oleh Mayapada Hospital.

\section{Saran Untuk Public Relations Pihak Mayapada}

Nurvita Indarini selaku Managing Editor detik.health, Lisvy Nael wartawan JawaPos, dan Elisabet Lisa reporter koran Kontan memberikan masukan kepada PR Mayapada Healthcare group agar lebih sering melakukan kegiatan media relations dengan media terutama detik.health. Waktu dalam melakukan kegiatan press conference agar diperpanjang atau terdapat beberapa sesi. Press realease lebih lengkap dengan materimateri kesehatan. Pihak media Kontan saja yang menganggap bahwa PR Mayapada selama ini tidak memiliki kendala, sehingga tidak ada masukan untuk MHG. 


\section{SIMPULAN}

Berdasarkan hasil penelitian, dapat memberikan kesimpulan bahwa Mayapada Healthcare Group telah melakukan kegiatan media relations yang telah berlangsung selama 1 tahun dengan lancar, dan tidak terdapat hambatan yang dipermasalahkan, dengan media cetak maupun online, baik dari media yang bersegmentasi kesehatan maupun bisnis, seperti detik.health, JawaPos, dan Kontan.

Pelaksanaan kegiatan media relations yang telah dilakukan diantaranya adalah press conference (4 kali dalam setahun), press/hospital tour (2 kali dalam setahun), press release, media gathering (1 kali dalam setahun), one on one interview, live chat (4 kali dalam setahun), sponsorship (12 kali dalam setahun), media visit (10 kali dalam setahun). Terdapat kegiatan media relations yang berbeda dengan yang dilakukan oleh perusahaan atau rumah sakit lain yaitu live chat, sponsorship dan one on one interview.

Kegiatan media relations yang membentuk citra Mayapada Hospital baik dari segi media dan pembaca berita adalah live chat, karena pada saat berkomunikasi melalui chatting secara langsung dengan membahas mengenai pertanyaan-pertanyaan yang diajukan oleh customer, dapat membentuk kepercayaan kepada dokter-dokter Mayapada Hospital yang memiliki kredibilitas tinggi. Kegiatan live chat ini mempunyai keuntungan bagi masyarakat, dan media, yaitu mereka mendapatkan ilmu dan pengetahuan yang lebih mendalam mengenai isu-isu kesehatan yang belum pernah mereka ketahui sebelumnya.

Proses sebelum melakukan kegiatan media relations, yang dilakukan tidak dengan cara mengirimkan press release, tetapi kedua belah pihak mengirimkan informasi atau undangan melalui aplikasi WhatsApp atau konfirmasi ulang melalui e-mail, atau mempertemukan kedua belah pihak antara perwakilan MHG dan pimpinan redaksi media untuk menyepakati kegiatan media relations yang akan dilakukan bersama.

Proses setelah melakukan kegiatan media relations, PR dari Mayapada Healthcare Group memberikan sebuah press kit yang berisi souvenir seputar Mayapada Hospital, kemudian memberikan press release dalam bentuk hard copy dan soft copy kepada wartawan media yang hadir. Setelah itu melakukan media monitoring dengan melihat berapa banyak coverage setelah kegiatan media relations dilakukan, dan apabila membutuhkan copy-an datanya untuk sebuah laporan, pihak dari PR Mayapada Healthcare Group meminta untuk mengirimkan coverage tersebut dalam bentuk soft atau hard copy, selain itu memeriksa kembali tulisan yang dimuat, adakah penyampaian kata-kata yang kurang memiliki news value atau sudah cukup sesuai dengan kebutuhan media.

Dari sisi media, setelah mengikuti kegiatan media relations yang dilakukan oleh pihak Mayapada, media langsung membuat artikel sebagai bahan pemberitaan mengenai Mayapada Hospital yang berasal dari informasi yang berasal dari narasumber Mayapada 
Hospital (CEO Mayapada Healthcare Group atau dokter-dokter pakar Mayapada Hospital) secara langsung.

Dari hasil kegiatan media relations berhasil membentuk citra yang diharapkan (wish image) Mayapada Hospital di mata media dan pihak eksternal rumah sakit yaitu pembaca berita, yang dilihat sebagai rumah sakit yang memiliki satu kesatuan baik, dilihat dari faktor identitas fisik, identitas non fisik, kualitas hasil, mutu dan pelayanan dan juga aktivitas dan pola hubungan.

\section{DAFTAR PUSTAKA}

Azizah, N. (2015). Mayapada Ekspansi 5 Rumah Sakit. Beritasatu.com. http://www.beritasatu.com/emiten/261330-mayapada-ekspansi-5-rumahsakit.html

Gassing, S. S. dan Suryanto. (2016). Public Relations. Yogyakarta: C.V ANDI OFFSET.

Isni, L. (2012). Jurnal Ilmu Komunikasi Interaksi. Media Relations dan Kepuasan Wartawan Atas Layanan Kehumasan di Kabupaten Brebes. 1(1). 87-97. Diperoleh dari http://ejournal.undip.ac.id/index.php/interaksi/article/view/4448

Kholisoh, N., \& Yenita. (2015). Jurnal Ilmu Komunikasi. Strategi Public Relations dan citra positif organisasi (Kasus Public Relations Rumah Sakit “X” di Jakarta. 13(3). 106209.

Diperoleh

dari

http://jurnal.upnyk.ac.id/index.php/komunikasi/article/view/1459/1333

Kurnia, E. (2016). Tingkatkan Kualitas, RS Swasta Ini Gandeng RS Singapura. Lifestyle.okezone.com. Diperoleh dari http://lifestyle.okezone.com/read/2016/04/26/481/1373236/tingkatkankualitas-rs-swasta-ini-gandeng-rs-singapura

Lillyah, A. (2016). Mayapada Hospital Tak Hanya Untuk Kelas Premium. Swa.co.id. Diperoleh dari http://swa.co.id/swa/ceo-interview/jonathan-tahir-mayapadahospital-tak-hanya-untuk-kelas-premium

Miles, M. B., Huberman, A. M., \& Saldana, J. (2014). Qualitative Data Analysis A Methods Sourcebook. United State of America: SAGE.

Moleong, L.J. (2010). Metodologi Penelitian Kualitatif. Bandung: PT Remaja Rosdakarya.

Morissan. (2010). Manajemen Public Relations: Strategi Menjadi Humas Profesional. Jakarta: Kencana. 
Pratiwi, E. N., Mayopu, G. R., \& Huwae, N. G. (2015). jurnal komunikasi ASPIKOM. Aktivitas Media Relations Humas Setda Kota Salatiga Dalam Membentuk Berita Positif. 5(2). 330-345. Diperoleh dari http://jurnal.aspikom.org/wpcontent/uploads/2016/04/4-JKA-Vol-2-No- 5-Nugrahaning-Esa-PratiwiRichard-Gordon-Mayopu-dan-George- Nicholas-Huwae.pdf

Soemirat, S. dan Ardianto, E. (2015). Dasar-Dasar Public Relations. Bandung: PT Remaja Rosdakarya.

Suryanto. (2015). Pengantar Ilmu Komunikasi. Bandung: CV PUSTAKA SETIA.

Yuliana, N. (2014). Media Relations. Yogyakarta: Graha Ilmu.

Yuningsih, A. (2005). Jurnal Ilmu Komunikasi. CSR Antara Publisitas, Citra, dan Etika, dalam profesi Public Relations. 6(2). 316-324. Diperoleh dari http://ejournal.unisba.ac.id/index.php/mediator/article/view/1211/753 